\title{
Potencial forrageiro de cultivares de girassol produzidos na safrinha para ensilagem
}

[Forage potential of sunflower cultivars produced in double-cropping system for silage]

\author{
T.R. Tomich ${ }^{1}$, J.A.S. Rodrigues ${ }^{2}$, L.C. Gonçalves ${ }^{3}$, R.G.P. Tomich ${ }^{4}$, A.U. Carvalho ${ }^{3}$ \\ ${ }^{1}$ EMBRAPA Pantanal \\ Caixa Postal 109 \\ 79320-900 - Corumbá, MS \\ ${ }^{2}$ EMBRAPA Milho e Sorgo - Sete Lagoas, MG \\ ${ }^{3}$ Escola de Veterinária da UFMG - Belo Horizonte, MG \\ ${ }^{4}$ Instituto de Ciências Biológicas da UFMG - Belo Horizonte, MG
}

Recebido para publicação em 22 de maio de 2003

Recebido para publicação, após modificações, em 2 de outubro de 2003

E-mail: thierry@cpap.embrapa.br

\section{RESUMO}

Avaliaram-se algumas características agronômicas relevantes de 12 híbridos e uma variedade de girassol (Helianthus annuus L.), participantes do ensaio nacional de girassol, no ano agrícola 1996/97, destinados à produção de silagem. $\mathrm{O}$ experimento foi conduzido de fevereiro a junho, utilizando-se delineamento experimental de blocos ao acaso e comparação das médias pelo teste Student-Newman-Keuls. Foram obtidas diferenças significativas entre os híbridos para as produções de matéria verde e de matéria seca, porcentagens de folha, de caule e de capítulo, circunferência do caule próximo ao capítulo, porcentagem de plantas quebradas e altura das plantas. Não foram encontradas diferenças significativas para circunferência do caule próximo ao solo, diâmetro do capítulo e porcentagem de plantas acamadas. As características agronômicas avaliadas indicaram que alguns híbridos de girassol apresentam potencial para serem utilizadas como recurso forrageiro para a produção de silagem na safrinha, ou durante o período seco do ano.

Palavras-chave: girassol, Helianthus annuus, características agronômicas, produtividade

\begin{abstract}
The objective of this study was to evaluate some important agronomic traits for silage production of 12 hybrids and a variety of sunflower (Helianthus annuus L.) participant of the national assay of sunflower, in the agricultural year of 1996/97. The experiment was conducted from February to June 1997. The experimental procedure followed a randomized block design and the means values were compared by Student-Newman-Keuls test. Significant differences among hybrids for fresh and dry matter productions, leaf, head and stem percentages, stem's circumference close the head, broken plants percentage and height of the plants were observed. No significant differences among hybrids for stem's circumference close the ground, diameter of the head and laying plants percentage were found. The agronomic traits indicated that some hybrids of sunflower present potential to be used for silage production in doublecropping system, or during the drought.
\end{abstract}

Keywords: sunflower, Helianthus annuus, agronomic traits, productivity

\section{INTRODUÇÃO}

O girassol é uma dicotiledônia anual caracterizada por apresentar sistema radicular com raiz principal pivotante e inflorescência conhecida como capítulo (Gonçalves, Tomich, 1999). A planta do girassol, os 
grãos, os restos da cultura e os subprodutos gerados na extração do óleo podem ser usados na alimentação animal. Na dieta de ruminantes o girassol pode ser utilizado como alimento volumoso. Na literatura são encontrados estudos sobre o uso das cascas dos grãos (Marx, 1977), da palhada (Drackley et al., 1985) e da planta inteira como forragem verde (Seiler, 1986; Lloveras, 1990) ou ensilada (Tosi et al., 1975; McGuffey, Schingoethe, 1980; Tomich et al., 2001). A alta eficiência em utilizar a água disponível no solo para o seu desenvolvimento, capaz de produzir grande quantidade de matéria seca sob condição de estresse hídrico (Sheaffer et al., 1977), e a tolerância à ampla faixa de temperaturas, sem redução significativa da produção (Castro et al., 1997), são fatores que estimulam o cultivo do girassol para a produção de forragem após a colheita da safra principal, como cultura de safrinha.

As plantas de girassol apresentam larga variação dos caracteres fenotípicos. De acordo com Castiglioni et al. (1994), são observadas plantas com alturas que variam de 50 a $400 \mathrm{~cm}$, caules de 15 a $90 \mathrm{~mm}$ de diâmetro, folhas de 8 a 50cm de comprimento e de 8 a 70 folhas por caule, capítulos com diâmetros de 6 a $50 \mathrm{~cm}$, que contêm de 100 a 8.000 flores. O peso de mil aquênios pode variar de 30 a $60 \mathrm{~g}$ e, segundo Castro et al. (1997), o número mais freqüente oscila de 800 a 1.700 por capítulo. Conforme Castiglioni et al. (1994), as características da planta, como altura, tamanho do capítulo e circunferência do caule, variam segundo o genótipo e as condições edafoclimáticas. Este trabalho teve como objetivo avaliar 12 híbridos e uma variedade de girassol cultivados no período de safrinha, estudando características agronômicas e morfológicas relevantes à sua utilização como planta forrageira para a ensilagem.

\section{MATERIAL E MÉTODOS}

Doze híbridos e uma variedade de girassol foram cultivados em Sete Lagoas, Minas Gerais. A região apresenta altitude média de 732 metros e, segundo a classificação de Köppen, clima do tipo AW (clima de savana, com inverno seco e temperatura média acima de $18^{\circ} \mathrm{C}$ no mês mais frio). Foram realizadas adubações no plantio (350kg da fórmula 04-14-08 por ha) e em cobertura (100kg de uréia por ha), de acordo com a análise do solo e as necessidades da cultura. O plantio foi efetuado dia 13 de fevereiro de 1997 e as colheitas em 28 de maio e 9 de junho de 1997. Cada cultivar foi plantado em quatro parcelas que continham quatro linhas de seis metros de comprimento, espaçadas por um metro entre si (parcelas de $6,0 \mathrm{~m} \times 3,0 \mathrm{~m})$.

Os híbridos AS243, AS603, Contiflor 3, M737, M742 e a variedade V2000 foram colhidos com 104 dias de idade e os híbridos Cargill 11, Contiflor 7, DK180, M734, M738, Rumbosol 90 e Rumbosol 91, com 116 dias, quando todos apresentavam acima de $90 \%$ dos grãos maduros. Imediatamente antes da colheita, nas duas linhas centrais dos canteiros, foram feitas determinações da curvatura do caule segundo Castiglioni et al. (1994), do número total de plantas, número de plantas acamadas, número de plantas quebradas, altura das plantas (nível do solo até a inserção do capítulo), diâmetro do capítulo e circunferências do caule (próximo ao capítulo e a $20 \mathrm{~cm}$ do solo). O corte das plantas foi feito manualmente, rente ao solo, nas duas fileiras centrais, descartando-se um metro nas cabeceiras. Todo o material cortado em cada canteiro foi pesado e a partir dele calculou-se o rendimento de matéria verde e de matéria seca.

Em cinco plantas de cada canteiro foi feita a separação em folhas, caule e capítulos. Essas porções da planta e parte do material colhido de cada parcela foram picadas em partículas de aproximadamente $2 \mathrm{~cm}$, secas em estufa de ventilação forçada a $65^{\circ} \mathrm{C}$ até peso constante, moídas em moinho com peneira de $1 \mathrm{~mm}$ e utilizadas para a determinação de matéria seca a $105^{\circ} \mathrm{C}$ segundo Association... (1995). Os resultados foram usados na determinação da porcentagem das diversas partes da planta e da produção de matéria seca. Utilizou-se delineamento experimental de blocos ao acaso, com 13 tratamentos (híbridos e variedade) e quatro repetições. Os dados foram analisados de acordo com o seguinte modelo estatístico:

$Y_{i j}=u+B_{i}+C_{j}+e_{i j}$, em que:

$\mathrm{Y}_{\mathrm{ij}}=$ observação relativa ao cultivar $\mathrm{j}$ no bloco i 
$\mathrm{u}=$ média geral

$\mathrm{B}_{\mathrm{i}}=$ efeito do bloco $\mathrm{i}(\mathrm{i}=1,2,3,4)$

$\mathrm{C}_{\mathrm{j}}=$ efeito do cultivar $\mathrm{j}(\mathrm{j}=1,2,3,4,5,6,7,8,9,11,12,13)$

$\mathrm{e}_{\mathrm{ij}}=$ erro experimental

Para a comparação das médias foi empregado o teste SNK $(\mathrm{P}<0,05)$. Também foram estimados os coeficientes de correlação entre as variáveis pelo coeficiente de correlação de Pearson. Para a análise dos dados, empregou-se o programa Sistema para Análises Estatísticas e Genéticas (SAEG) segundo Euclydes (1983).

\section{RESULTADOS E DISCUSSÃO}

A população de plantas no momento do corte, determinada pelo número de plantas colhidas, convertido para número de plantas por hectare, variou de 33.125 a 35.625 plantas/ha, sem diferença significativa entre os cultivares, indicando uniformidade de plantio para os tratamentos. A média geral de 34.407 plantas/ha ficou dentro da faixa normal para a época de colheita, entre 30.000 a 60.000 plantas/ha, de acordo com Gonçalves et al. (1981), mas abaixo da densidade de 40.000 a 45.000 plantas/ha, atualmente recomendada para a cultura do girassol (Gonçalves, Tomich, 1999).

A produção de matéria verde variou de 12,8 t/ha, variedade V2000 e híbrido Cargill 11, a 29,1 t/ha, híbrido Rumbosol 91 (Tab. 1). A produção de matéria seca variou de 3,6 a 7,7 t/ha, variedade V 2000 e híbrido Rumbosol 91, respectivamente. A correlação estimada entre produção de matéria verde e de matéria seca foi de $0,89(\mathrm{P}<0,05)$.

Tabela 1. Produção de matéria verde e de matéria seca de cultivares de girassol

\begin{tabular}{lcc}
\hline Híbrido ou & \multicolumn{2}{c}{ Produção (t/ha) } \\
\cline { 2 - 3 } variedade & Matéria verde & Matéria seca \\
\hline AS243 & 26,3AB & $7,0 \mathrm{AB}$ \\
AS603 & 23,9ABC & $5,8 \mathrm{ABC}$ \\
Cargill 11 & 12,8E & 4,7CD \\
Contiflor 3 & 26,4AB & $6,8 \mathrm{ABC}$ \\
Contilfor 7 & 15,6DE & $6,0 \mathrm{ABC}$ \\
DK180 & 19,2BCDE & $5,3 \mathrm{BCD}$ \\
M734 & 22,1ABCD & $6,4 \mathrm{ABC}$ \\
M737 & 29,1A & $6,7 \mathrm{ABC}$ \\
M738 & 17,9CDE & $5,6 \mathrm{ABC}$ \\
M742 & 24,7ABC & $6,5 \mathrm{ABC}$ \\
Rumbosol 90 & 15,9DE & $5,2 \mathrm{BCD}$ \\
Rumbosol 91 & $29,1 \mathrm{~A}$ & $7,7 \mathrm{~A}$ \\
V2000 & 12,8E & $3,6 \mathrm{D}$ \\
Média & 21,2 & 5,9 \\
CV $(\%)$ & 16,8 & 16,8 \\
\hline
\end{tabular}

Médias seguidas por letras distintas na coluna diferem $(\mathrm{P}<0,05)$ entre si pelo teste SNK.

A produção média de matéria seca, 5,9 t/ha, ficou próxima aos valores encontrados por Tosi et al. (1975) e Gonçalves et al. (1996) para semeadura em março e cortes com 83, 93 e 103 dias de idade, e por Silva et al. (1998), para a densidade de semeadura de 30.000 plantas/ha. Produções mais altas foram observadas por Gonçalves et al. (1996), para plantio em fevereiro e corte com 103 dias, e Silva et al. (1998), para o plantio com densidades de 50.000 e 70.000 plantas/ha. Variabilidade genética, fertilidade do solo, disponibilidade de água, época de plantio, estádio de desenvolvimento da planta e número de plantas por unidade de área são alguns dos fatores capazes de influenciar a produtividade do girassol cultivado para silagem. 
Sheaffer et al. (1977) e Silva et al. (1998) observaram elevação na produção de matéria seca com o aumento na população de plantas. Silva et al. (1998) verificaram que a densidade de semeadura afetou linear e positivamente a produção de matéria seca total e dos diversos componentes da planta (caules, folhas, receptáculos e aquênios). No presente trabalho, a produção média de matéria seca pode ter sido limitada pelo menor número de plantas por unidade de área, quando comparado a alguns estudos que apresentaram produções superiores. Assim, acredita-se que produções mais elevadas poderiam ter sido alcançadas caso tivesse sido adotada a atual recomendação de Gonçalves e Tomich (1999) quanto à densidade de cultivo (40.000 a 45.000 plantas/ha).

Brito et al. (2000), ao avaliarem a produtividade de sete genótipos de sorgo para a ensilagem, plantados no final do mês de janeiro no mesmo local de cultivo do atual experimento, obtiveram rendimento médio de 25,2 t/ha de matéria verde e 6,8 t/ha de matéria seca. No presente estudo, os híbridos AS243, Contiflor 3 e Rumbosol 91 apresentaram média de produção de matéria verde acima de 26,0 t/ha e os híbridos AS243, Contiflor 3 e Rumbosol 91 apresentaram média de produção de matéria seca igual ou superior a 6,8 t/ha. Esse fato indica que em relação ao rendimento forrageiro, alguns híbridos de girassol podem ser uma alternativa para a produção de silagem na safrinha, após a retirada da cultura de verão.

Na Tab. 2 estão as médias obtidas para folhas, caule e capítulo como porcentagem da matéria seca total dos cultivares. Os híbridos Rumbosol 91, com 25,0\%, e Rumbosol 90, com 22,5\%, apresentaram maiores proporções de folhas em relação à variedade V2000 (16,1\%) e ao híbrido M737 (15,8\%), enquanto que os demais híbridos apresentaram valores entre 17,5\% e 21,7\%, sem diferenças significativas entre si. Para a porcentagem de caule, a média do cultivar Contiflor 3, 28,7\%, ficou abaixo das proporções de 38,6\% do Rumbosol 91 e 39,3\% do Rumbosol 90. Nos demais cultivares as médias foram de 31,7\% a 35,2\%, também sem apresentarem diferenças entre si. O híbrido Rumbosol 91 apresentou 36,4\% de capítulo, semelhante aos 38,2\% observados para o Rumbosol 90 e inferior às médias obtidas para o restante dos cultivares, cuja variação foi de $45,5 \%$ a 51,6\%. Fernandes et al. (1999), ao avaliarem quatro cultivares de girassol, observaram teores decrescentes de fibra em detergente neutro para capítulo, folha e caule, teores crescentes de proteína bruta para caule, capítulo e folhas, e valores crescentes de fósforo e digestibilidade para caule, folha e capítulo. Pentreath et al. (2002), ao estudarem a digestibilidade das silagens de quatro cultivares de girassol com diferentes proporções de capítulo/caule mais folhas, notaram que, independente do cultivar, a digestibilidade foi maior com o aumento da participação dos capítulos na confecção da silagem. Assim, a determinação das proporções dessas frações da planta constitui um parâmetro importante na avaliação de genótipos de girassol para a ensilagem, sendo preferível os que apresentem menor porcentagem de caule e maiores porcentagens de folhas e de capítulo.

Na Tab. 3 estão as médias de circunferências do caule e de diâmetro do capítulo dos cultivares. A circunferência do caule próxima ao solo foi semelhante $(\mathrm{P}>0,05)$ para todos os cultivares, média de 24,3cm. Próxima ao capítulo, a variedade V2000 apresentou a maior média de circunferência em relação às médias dos demais cultivares. Sheaffer et al. (1977) verificaram que as plantas de culturas com alta densidade apresentaram caules finos e Nepomuceno e Silva (1992) também encontraram redução no diâmetro do caule com o aumento da densidade. Concluíram que tanto o aumento da altura como o decréscimo do diâmetro do caule, ocasionados pelo aumento da densidade, podem ser atribuídos à maior competição intraespecífica que se estabelece nessa condição, especialmente por luz incidente. Como neste experimento o número de plantas por área apresentou apenas variações mínimas entre os cultivares, acredita-se que a maior circunferência do caule próximo ao capítulo obtida para o V2000 seja determinada principalmente pelo efeito da variedade. Também não houve diferença significativa entre os cultivares quanto ao diâmetro do capítulo. A média geral, $17,3 \mathrm{~cm}$ ficou acima do valor de $15,5 \mathrm{~cm}$ observado por Solasi e Mundstock (1992) para três cultivares plantados em outubro, no Estado do Rio Grande do Sul, e abaixo dos valores de $18,4 \mathrm{~cm}$ e $22,6 \mathrm{~cm}$ e próximo aos $16,6 \mathrm{~cm}$ encontrados por Nepomuceno e Silva (1992), também no Rio Grande do Sul, em densidades de 50.000, 30.000 e 70.000 plantas/ha, respectivamente. Observou-se correlação positiva $(\mathrm{P}<0,01)$ entre o diâmetro do capítulo e a circunferência do caule próximo ao capítulo, característica importante, pois pode contribuir para reduzir a perda de capítulos que tende a ocorrer principalmente em culturas sob condições de estresse hídrico acentuado e de deficiência de boro. 
Tabela 2. Porcentagens de folhas, caule e capítulo na matéria seca total de cultivares de girassol

\begin{tabular}{lccc}
$\begin{array}{l}\text { Híbrido ou } \\
\text { variedade }\end{array}$ & $\begin{array}{c}\text { Folhas } \\
(\%)\end{array}$ & $\begin{array}{c}\text { Caule } \\
(\%)\end{array}$ & $\begin{array}{c}\text { Capítulo } \\
(\%)\end{array}$ \\
\hline AS243 & $20,5 \mathrm{ABC}$ & $34,1 \mathrm{AB}$ & $45,5 \mathrm{AB}$ \\
AS603 & $20,0 \mathrm{ABC}$ & $32,9 \mathrm{AB}$ & $47,1 \mathrm{AB}$ \\
Cargill 11 & $18,9 \mathrm{BC}$ & $33,9 \mathrm{AB}$ & $47,2 \mathrm{AB}$ \\
Contiflor 3 & $20,4 \mathrm{ABC}$ & $28,7 \mathrm{~B}$ & $50,8 \mathrm{~A}$ \\
Contilfor 7 & $21,7 \mathrm{ABC}$ & $32,1 \mathrm{AB}$ & $46,2 \mathrm{AB}$ \\
DK180 & $20,3 \mathrm{ABC}$ & $35,2 \mathrm{AB}$ & $44,5 \mathrm{AB}$ \\
M734 & $19,0 \mathrm{BC}$ & $32,5 \mathrm{AB}$ & $48,5 \mathrm{~A}$ \\
M737 & $15,8 \mathrm{C}$ & $32,6 \mathrm{AB}$ & $51,6 \mathrm{~A}$ \\
M738 & $18,2 \mathrm{BC}$ & $31,7 \mathrm{AB}$ & $50,1 \mathrm{~A}$ \\
M742 & $17,5 \mathrm{BC}$ & $31,8 \mathrm{AB}$ & $50,7 \mathrm{~A}$ \\
Rumbosol 90 & $22,5 \mathrm{AB}$ & $39,3 \mathrm{~A}$ & $38,2 \mathrm{BC}$ \\
Rumbosol 91 & $25,0 \mathrm{~A}$ & $38,6 \mathrm{~A}$ & $36,4 \mathrm{C}$ \\
V2000 & $16,1 \mathrm{C}$ & $34,0 \mathrm{AB}$ & $49,9 \mathrm{~A}$ \\
Média & 19,7 & 33,7 & 46,7 \\
CV (\%) & 18,1 & 10,3 & 9,1 \\
\hline
\end{tabular}

Médias seguidas por letras distintas na coluna diferem entre si $(\mathrm{P}<0,05)$ pelo teste SNK.

Tabela 3. Circunferência do caule e diâmetro do capítulo de cultivares de girassol

\begin{tabular}{lccc}
\hline \multirow{3}{*}{$\begin{array}{l}\text { Híbrido ou } \\
\text { variedade }\end{array}$} & \multicolumn{2}{c}{$\begin{array}{c}\text { Circunferência do caule } \\
(\mathrm{cm})\end{array}$} & $\begin{array}{c}\text { Diâmetro do } \\
\text { capítulo }(\mathrm{cm})\end{array}$ \\
\cline { 2 - 3 } & $\begin{array}{c}\text { Próximo } \\
\text { ao solo }\end{array}$ & $\begin{array}{c}\text { Próximo ao } \\
\text { capítulo }\end{array}$ & \\
\hline AS243 & 23,8 & $11,2 \mathrm{~B}$ & 16,0 \\
AS603 & 25,2 & $13,4 \mathrm{~B}$ & 16,6 \\
Cargill 11 & 24,4 & $11,3 \mathrm{~B}$ & 17,5 \\
Contiflor 3 & 22,3 & $12,8 \mathrm{~B}$ & 17,8 \\
Contilfor 7 & 22,9 & $11,7 \mathrm{~B}$ & 17,3 \\
DK180 & 24,3 & $11,9 \mathrm{~B}$ & 18,2 \\
M734 & 23,8 & $11,3 \mathrm{~B}$ & 17,1 \\
M737 & 26,0 & $13,1 \mathrm{~B}$ & 17,3 \\
M738 & 24,6 & $11,4 \mathrm{~B}$ & 16,4 \\
M742 & 23,5 & $12,7 \mathrm{~B}$ & 17,5 \\
Rumbosol 90 & 25,7 & $12,2 \mathrm{~B}$ & 15,9 \\
Rumbosol 91 & 24,7 & $11,5 \mathrm{~B}$ & 18,7 \\
V2000 & 25,3 & $19,3 \mathrm{~A}$ & 18,4 \\
Média & 24,3 & 12,6 & 17,3 \\
CV (\%) & 7,3 & 9,2 & 8,4 \\
\hline Médias seguidas por letras distintas na coluna diferem (P<0,05) entre si pelo teste SNK.
\end{tabular}

As porcentagens de plantas acamadas e de plantas quebradas no momento do corte são mostradas na Tab. 4. Elevado número de plantas acamadas ou quebradas relaciona-se à menor eficiência na colheita e a maiores perdas da cultura. Todos os cultivares apresentaram baixa porcentagem de acamamento, com o valor máximo de $1,3 \%$ para o híbrido Contiflor 7 , não significativamente diferente dos demais. A porcentagem de plantas acamadas foi negativamente correlacionada com a circunferência do caule próximo ao solo. O híbrido Rumbosol 91 apresentou 14,6\% de plantas quebradas, valor superior $(\mathrm{P}<0,05)$ às porcentagens médias obtidas para os outros cultivares, que se equivaleram. A maior percentagem de quebra para o híbrido Rumbosol 91 talvez seja explicada por sua maior estatura. Nepomuceno e Silva (1992) não notaram aumento na percentagem de plantas acamadas ou quebradas, provocado pelo aumento da altura quando elevaram o número de plantas por hectare, atribuindo esse fato, em parte, à redução concomitante do tamanho do capítulo. 
Na Tab. 5 são apresentadas as médias de curvatura do caule e de altura das plantas. Segundo Castiglioni et al. (1994), a curvatura do caule apresenta sete classificações, variando de plantas com caule reto e capítulos voltados para cima (1) a plantas com caule quebrado com capítulo aderido ou se desprendendo do caule (7). Neste trabalho foram obtidas classificações de 3 (caule curvado cerca de $15 \%$ do comprimento total da planta) a 5 (caule curvado entre 36\% e $65 \%$ do comprimento total da planta), sem variações entre as repetições de um mesmo cultivar. Estes resultados são favoráveis, uma vez que as plantas com classificação intermediária (inclinação média) são as mais desejadas, por apresentarem menor risco de danos provocados por pássaros e pela dificuldade de escoamento de água dos capítulos, como ocorre com as plantas de classificação 1, ou de perdas de capítulo durante a colheita mecanizada, com maior propensão de acontecer na classificação 7.

Tabela 4. Porcentagem de plantas acamadas e de plantas quebradas de cultivares de girassol

\begin{tabular}{lcc} 
Tratamento & $\begin{array}{c}\text { Plantas acamadas } \\
(\%)\end{array}$ & $\begin{array}{c}\text { Plantas quebradas } \\
(\%)\end{array}$ \\
\hline AS243 & 0,6 & $0,0 \mathrm{~B}$ \\
AS603 & 0,0 & $1,2 \mathrm{~B}$ \\
Cargill 11 & 0,0 & $0,6 \mathrm{~B}$ \\
Contiflor 3 & 1,2 & $3,0 \mathrm{~B}$ \\
Contilfor 7 & 1,3 & $4,2 \mathrm{~B}$ \\
DK180 & 0,6 & $0,0 \mathrm{~B}$ \\
M734 & 0,0 & $2,4 \mathrm{~B}$ \\
M737 & 0,6 & $0,0 \mathrm{~B}$ \\
M738 & 0,0 & $0,0 \mathrm{~B}$ \\
M742 & 0,6 & $1,2 \mathrm{~B}$ \\
Rumbosol 90 & 0,0 & $0,6 \mathrm{~B}$ \\
Rumbosol 91 & 0,0 & $14,6 \mathrm{~A}$ \\
V2000 & 0,0 & $0,7 \mathrm{~B}$ \\
Média & 0,4 & 2,2 \\
CV (\%) & 231,0 & 152,5 \\
Médias seguidas por letras distintas na coluna diferem $(\mathrm{P}<0,05)$ entre si pelo teste SNK.
\end{tabular}

A variedade V2000, com a média de $178 \mathrm{~cm}$, foi o cultivar mais baixo $(\mathrm{P}<0,05)$, e o híbrido Rumbosol 91, com $268 \mathrm{~cm}$, o mais alto $(\mathrm{P}<0,05)$. Para um mesmo cultivar, a altura está relacionada à qualidade do solo (Kakida, 1981), à presença de plantas invasoras (Fleck, 1991) e ao espaçamento entre linhas (Nepomuceno, Silva, 1992). A altura é uma característica importante por ser, normalmente, positivamente correlacionada com as características de produção. Segundo Pizzarro (1978) e Zago (1997), há correlação positiva entre altura da planta e produção de matéria seca para as culturas de milho e de sorgo, respectivamente. Neste estudo também foram observadas correlações positivas entre a altura das plantas e as produções de matéria verde $(\mathrm{r}=0,41 ; \mathrm{P}<0,05)$ e de matéria seca $(\mathrm{r}=0,52 ; \mathrm{P}<0,05)$. Contudo, também foi positiva a correlação entre a altura e a porcentagem de plantas quebradas $(\mathrm{r}=0,65 ; \mathrm{P}<0,05)$ e entre altura e a porcentagem de caule $(\mathrm{r}=0,40 ; \mathrm{P}<0,05)$, que são características indesejáveis quando se pretende produção eficiente e forragem de qualidade. 
Tabela 5. Curvatura do caule e altura da planta de cultivares de girassol

\begin{tabular}{lcc}
$\begin{array}{l}\text { Híbrido ou } \\
\text { variedade }\end{array}$ & $\begin{array}{c}\text { Curvatura } \\
\text { do caule }\end{array}$ & $\begin{array}{c}\text { Altura da } \\
\text { planta }(\mathrm{cm})\end{array}$ \\
\hline AS243 & 3 & 200BCD \\
AS603 & 4 & 203BC \\
Cargill 11 & 4 & 184CD \\
Contiflor 3 & 4 & 198BCD \\
Contilfor 7 & 3 & $214 \mathrm{~B}$ \\
DK180 & 4 & $213 \mathrm{~B}$ \\
M734 & 5 & $209 \mathrm{~B}$ \\
M737 & 5 & 200BCD \\
M738 & 5 & 195BCD \\
M742 & 4 & 194BCD \\
Rumbosol 90 & 3 & $215 \mathrm{~B}$ \\
Rumbosol 91 & 3 & 268A \\
V2000 & 4 & 205 \\
Média & --- & 6,0 \\
CV (\%) & --- &
\end{tabular}

\section{CONCLUSÕES}

A produtividade média alcançada por alguns híbridos revelam o potencial da cultura do girassol como recurso forrageiro para ensilagem em período de safrinha. O híbrido Contiflor 3 se destaca quando se considera o rendimento forrageiro e a proporção favorável de partes da planta. As pequenas variações observadas para circunferências de caule e de capítulo e para as porcentagens de plantas acamadas e quebradas dificultam a indicação dos cultivares a serem usados quanto a essas características. Todos eles apresentaram curvatura do caule favorável à minoração de perdas. As correlações positivas entre produção forrageira e porcentagens de plantas quebradas e de caule assinalam a necessidade de cautela na utilização da altura como critério para a escolha de cultivares.

\section{REFERÊNCIAS BIBLIOGRÁFICAS}

ASSOCIATION of Official Analytical Chemists - AOAC. Official methods of analysis. 16ed. Washington: AOAC, 1995. 2000p.

BRITO, A.F.; GONÇALVES, L.C.; RODRIGUES, J.A.S. et al. Avaliação da silagem de sete genótipos de sorgo [Sorghum bicolor (L) Moench]. I. características agronômicas. Arq. Bras. Med. Vet. Zootec., v.52, p.391-396, 2000.

CASTIGLIONI, V.B.R.; BALLA, A.; CASTRO, C. et al. Fases de desenvolvimento da planta de girassol. Londrina: Embrapa-CNPSo, 1994. 24p. (Documentos, 58)

CASTRO, C.; CASTIGLIONI, V.B.R.; BALLA, A. et al. A cultura do girassol. Londrina: EmbrapaCNPSo, 1997. 36p. (Circular Técnica, 13)

DRACKLEY, J.K.; CLARK, A.K.; SAHLU, T. Evaluation of sunflower crop residue in rations for growing Holstein heifers. J. Dairy Sci., v.68, p.2390-2395, 1985.

EUCLYDES, R.F. Manual de utilização do programa SAEG (Sistema para Análises Estatísticas e Genéticas). Viçosa: UFV, 1983. 59p.

FLECK, N.G. Época de capinas para controle de plantas daninhas em girassol. Pesq. Agropec. Bras., v.26, p.1509-1516, 1991. 
FERNANDES, F.D.; AMABILE, R.F.; GOMES, A.C. Teores de nutrientes, fibra em detergente neutro e digestibilidade in vitro da matéria seca de folhas, caules e capítulos girassol. In: REUNIÃO NACIONAL DE PESQUISA DE GIRASSOL, 13., 1999, Itumbiara. Anais... Londrina: Embrapa Soja, 1999. p.67-68.

GONÇALVES, L.C.; SILVA, F.F.; CORREA, C.E.S. et al. A. Produtividade e teor de matéria seca de girassol (Helianthus annus) cultivado em diferentes épocas do ano e colhido em diferentes estágios vegetativos. In: REUNIÃO ANUAL DA SOCIEDADE BRASILEIRA DE ZOOTECNIA, 33., 1996, Fortaleza. Anais... Fortaleza: UFC, 1996. v.2, p.377-379.

GONÇALVES, L.C.; TOMICH, T.R. Utilização do girassol como silagem para alimentação bovina. In: REUNIÃO NACIONAL DE PESQUISA DE GIRASSOL, 13., 1999, Itumbiara. Anais..., Londrina: Embrapa Soja, 1999. p.21-30.

GONÇALVES, N.P.; KAKIDA, J.; MARINATO, R. et al. Época, espaçamento, densidade de plantio e irrigação para a cultura do girassol. Inf. Agropec., v.7, p.78-80, 1981.

KAKIDA, J.; GONÇALVES, N.P.; MARCIANI-BENDEZÚ, J. et al. Cultivares de girassol. Inf. Agropec., v.7, p.76-78, 1981.

LLOVERAS, J. Dry matter yield and nutritive value of four summer annual crops in north-west Spain (Galicia). Grass Forage Sci., v.45, p.243-248, 1990.

MARX, G.D. Utilization of sunflower silage, sunflower hulls with poultry litter and sunflower hulls mixed with corn silage for growing dairy animals. J. Dairy Sci., v.60, p.112, 1977.

McGUFFEY, R.K.; SCHINGOETHE, D.J. Feeding value of high oil variety of sunflowers as silage to lactating dairy cows. J. Dairy Sci., v.63, p.1109-1113, 1980.

NEPOMUNCENO, A.L.; SILVA, P.R.F. Efeito do arranjo de plantas e da presença de ervas daninhas nas características de plantas associadas à colheita de girassol. Pesq. Agropec. Bras., v.27, p.1057-1063, 1992.

PENTREATH, M.; NOGUERA, J.R.R.; GONÇALVES, L.C. et al. Digestibilidade in vitro do material integral e desengordurardo de quatro cultivares de girassol Helianthus annuus L. ensilados com diferentes proporções da planta. In: REUNIÃO ANUAL DA SOCIEDADE BRASILEIRA DE ZOOTECNIA, 39., 2002. Recife. Anais... São Paulo: Gmosis, 2002. CD-ROM. Nutrição de ruminantes.

PIZARRO, E.A. Conservação de forragens. I. Silagem. Inf. Agropec., v.4, p.20-30, 1978.

SEILER, J.S. Forage quality of selected wild sunflower species. Agron. J., v.78, p.1059-1064, 1986.

SILVA, A.W.L.; MACEDO, A.F.; HOESCHL NETO, W. et al. Efeito da semeadura de densidade sobre a produtividade e composição bromatológica de silagens de girassol. In: REUNIÃO ANUAL DA SOCIEDADE BRASILEIRA DE ZOOTECNIA, 35., 1998, Botucatu. Anais... Botucatu: FMVZ-UNESP, 1998. p.635-637.

SHEAFFER, C.C.; McNEMAR, J.H.; CLARK, N.A. Potential of sunflowers for silage in doublecropping systems following small grains. Agron. J., v.69, p.543-546, 1977.

SOLASI, A.D.; MUNDSTOCK, C.M. Épocas de semeadura e características do capítulo de cultivares de girassol. Pesq. Agropec. Bras., v.27, p.873-879, 1992.

TOMICH, T.R.; GONÇALVES, L.C.; RODRIGUES, J.A.S. et al. Avaliação de treze genótipos de girassol (Helianthus annuus L.) 1. composição química da forragem fresca e das silagens. In: REUNIÃO ANUAL DA SOCIEDADE BRASILEIRA DE ZOOTECNIA, 38, 2001, Piracicaba. Anais... Piracicaba: ESALQ-USP, 2001. p.298-299.

TOSI, H.; SILVEIRA, A.C.; FARIA, V.P. et al. Avaliação do girassol (Helianthus annus) como planta para a ensilagem. Rev. Soc. Bras. Zootec., v.4, p.39-48, 1975.

ZAGO, C.P. Utilização do sorgo na alimentação de ruminantes. In: MANEJO CULTURAL DO SORGO PARA FORRAGEM. Sete Lagoas: Embrapa-CNPMS, 1997. p.9-26. (Circular Técnica, 17). 